J. Gen. Appl. Microbiol.

Vol. 11, No. 3, 1965

\title{
ROLE OF ALANINE IN THE SPORE GERMINATION OF BACILLUS SUBTILIS
}

\author{
HITOSHI UCHIYAMA ${ }^{1}$ \\ Tokai Regional Fisheries Reszarch Laboratories, Fisheries Agency, \\ Ministry of Agriculture and Forestry, Tsukishima, Tokyo \\ KENJI TANAKA and TOMOMICHI YANAGITA \\ Institute of Applied Microbiology, University of Tokyo \\ Bunkyo-ku, Tokyo \\ Received August 13, 1965
}

L-Alanine has been known to be one of the essential nutrients in the spore germination of certain bacterial species (1, 2, 3). Although the metabolic pathway of L-alanine in germinating spores has been extensively studied by several workers $(4,5)$, the role of this amino acid in the spore germination is still obscure. Hoshino et al. (6) employed Aspergillus niger conidia instead of bacterial spores and showed that L-alanine plays an important role in the nucleic acid metabolism in the early phase of germination. They also noticed that the fate of L-alanine is quite similar to that of $\mathrm{CO}_{2}$ in the germinating conidia $(y)$.

The present investigation was performed to compare and clarify the role of $\mathrm{CO}_{2}$, alanine and other amino acids in spore germination, employing Marburg strain of Bacillus subtilis as the test organism. The results indicate that $\mathrm{CO}_{2}$ is not an essential factor for bacterial spore germination as it is in fungal conidia germination, and that L-alanine appears to play an important role in RNA metabolism during the processes of germination and outgrowth; during the latter process the concomitant presence of L-glutamate is required.

\section{MATERIALS AND METHODS}

Organism and collection of spores. Bacillus subtilis Marburg strain supplied by the courtesy of Dr. H. SaIto (Institute of Applied Microbiology, University of Tokyo) was used throughout this investigation. Spores were collected from a $72 \mathrm{hr}$ culture (at $37^{\circ}$ ) on nutrient agar and clean spores separated from contaminating vegetative cells by the method of IRIE and Uchirama (8). Spores were then lyophilized and stored at $-20^{\circ}$.

Cultivation of spores. Prior to cultivation, the spores were heated in distilled water for $15 \mathrm{~min}$ at $65^{\circ}$ at a concentration of $20 \mathrm{mg}$ dry spores per $\mathrm{ml}$. The heat shocked spores were cultured, unless otherwise stated,

1 Contribution from the Tokai Regional Fisheries Research Laboratories (Contrib. No. B 433) 
in Demain's medium (9) composed of per liter: $\mathrm{K}_{2} \mathrm{HPO}_{4}, 30 \mathrm{~g} ; \mathrm{KH}_{2} \mathrm{PO}_{4}, 10 \mathrm{~g}$; $\mathrm{NH}_{4} \mathrm{Cl}, 5 \mathrm{~g} ; \mathrm{NH}_{4} \mathrm{NO}_{3}, 1 \mathrm{~g}$; L-alanine, $0.89 \mathrm{~g} ;$ L-glutamic acid, $1.47 \mathrm{~g}$; L-asparagine, $1.32 \mathrm{~g} ; \mathrm{Na}_{2} \mathrm{SO}_{4}, 1 \mathrm{~g} ; \mathrm{MgSO}_{4} \cdot 7 \mathrm{H}_{2} \mathrm{O}, 100 \mathrm{mg} ; \mathrm{MnSO}_{4} \cdot 4 \mathrm{H}_{2} \mathrm{O}$, $10 \mathrm{mg} ; \mathrm{FeSO}_{4} \cdot 7 \mathrm{H}_{2} \mathrm{O}, 10 \mathrm{mg} ; \mathrm{CaCl}_{2}, 5 \mathrm{mg}$; and $\mathrm{pH}$ adjusted to 7.0. Inoculum was $1 \mathrm{mg}$ of dry spores per $1 \mathrm{ml}$ of medium. For testing the effect of amino acids on germination, a desired amino acid(s) was added to this basal medium but without L-alanine, L-glutamic acid and L-asparagine.

The course of germination was followed by measuring optical density at $550 \mathrm{~m} \mu$ and by examining microscopically the stainability with methylene blue. Under the culture conditions, the optical density decreased by 54\% during the initial $20 \mathrm{~min}$ and the stainability changed rather abruptly showing the high synchrony of germination.

Fractionation and analysis of cellular components. Cellular components were fractionated by the method of Schmidt-Thannhauser (10). The duration of the $5 \%$ perchloric acid (PCA) extraction was $18 \mathrm{hr}$ at $0^{\circ}$. The phosphorus content in the acid soluble fraction was determined by KING's method (11). RNA and DNA were estimated, respectively, by the orcinol (yeast RNA as standard, 10) and BurTon's method (calf thymus DNA “Sigma" as standard, 12).

Incorporation of alanine $-{ }^{14} C$ into spores. For the alanine $-{ }^{14} C$ incorporation experiments, the concentration of L-alanine in DemaIN's medium was reduced to $10 \%$ of the original concentration and to this was added L-alanine-U- ${ }^{14} \mathrm{C}$ (Daiichi Pure Chemicals \& Co.; specific activity, $2-5 \mathrm{mc}$ per mmole) at a final concentration of $0.1 \mu \mathrm{c}$ per ml.

For the estimation of the incorporation into whole cells, $1 \mathrm{ml}$ samples were taken at intervals from the culture, filtered by suction through a membrane filter (Membranfiltergesellschaft, Nr. 1) and washed thoroughly with water. The cell sample thus collected on a membrane filter was attached on a planchette, dried and the radioactivity measured.

In fractionation experiments, cells collected from a $10 \mathrm{ml}$ sample by centrifugation were subjected to fractionation by the SchmidT-THANNHAUSER method. Some fractions containing PCA were neutralized with $\mathrm{KOH}$ and the radioactivity of each fraction estimated. The radioactivity distribution among RNA bases was examined as follows: after hydrolysis of the RNA fraction with $60 \% \mathrm{PCA}$ at $100^{\circ}$ for $30 \mathrm{~min}$, an aliquot was paper chromatographed on a Whatman No. 1 filter paper strip with a solvent system of isopropanol-HCl-water $(34: 8: 8)$ and the radioactivity of each section of $1 \mathrm{~cm}$ in length scanned.

\section{RESULTS}

Effect of $\mathrm{CO}_{2}$ on germination

Yanagita ( 7$)$ found that $A$. niger conidia cannot swell nor germinate in a complete medium in the absence of $\mathrm{CO}_{2}$. To examine this possibility in $B$. subtilis spores, the spores were cultured in complete Demarn's medium 
with vigorous bubbling of air freed from $\mathrm{CO}_{2}$ by repeated washings with $\mathrm{KOH}$ solutions. Experiments showed that the spores were able to germinate as rapidly as those cultured in the same medium with vigorous bubbling of atmospheric air.

Effect of alanine, asparagine and glutamate on germination and outgrowth

To study further the findings of $\mathrm{H}_{\text {Achisuka }}$ et al. (13) and Demain (9), the effects of L-alanine, L-asparagine and L-glutamate on the germination and outgrowth were examined. As in Fig. 1A, when they were added to the basal

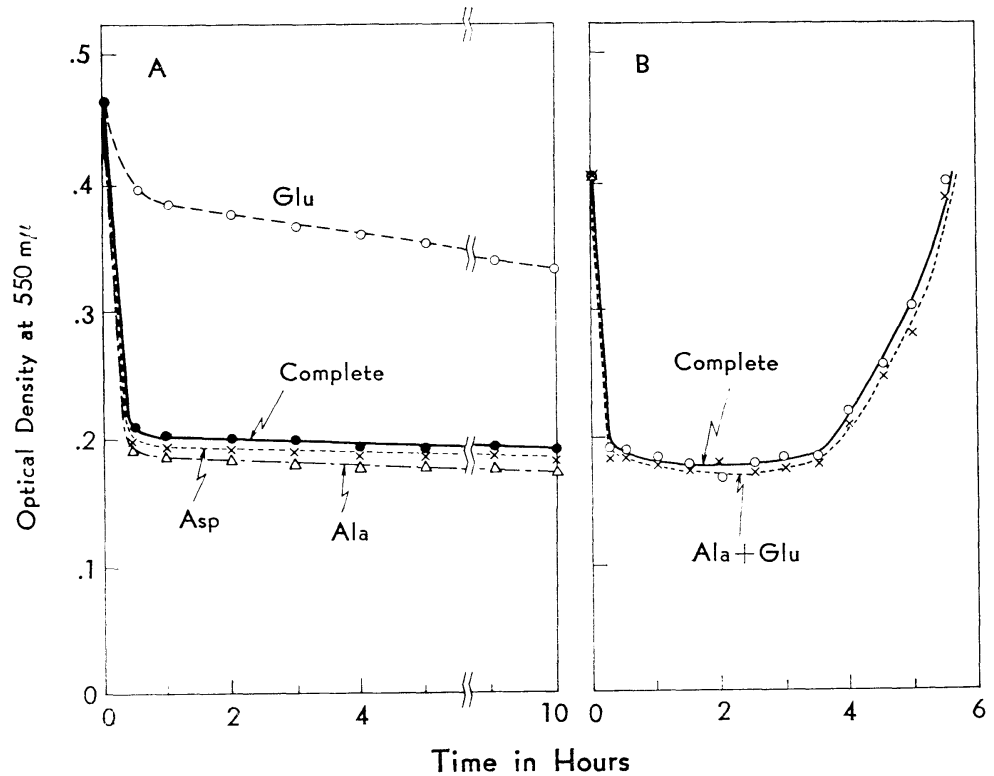

Fig. 1. Growth response of $B$. subtilis to various amino acids as determined by change in optical density at $550 \mathrm{~m} \mu$.

Cultivations of heat-shocked spores were performed in DEMAIN's media (Complete) being deprived of either one or two of 3 amino acids, e.g., L-alanine (Ala), L-asparagine (Asp) and L-glutamate (Glu).

A. Cultivation without shaking in media containing single amino acids noted (control being complete medium).

B. Cultivation with shaking in media containing pairs of amino acids noted (control being complete medium).

medium singly, alanine and asparagine were as effective as the complete medium in inducing germination, whereas glutamate was almost ineffective. In these cases, however, no sign of spore outgrowth (increase in optical density and stainability) was observed until $10 \mathrm{hr}$ even in the complete medium. This seemed to be caused by an oxygen deficiency resulting from the static cultivation. When the culture was aerated, outgrowth of spores after $5.5 \mathrm{hr}$ was noticed in the complete medium (Fig. 1B). In the presence of alanine and glutamate, germination and outgrowth also 
occurred normally when the culture was shaken vigorously. Thus it seems highly probable that the growth response of this spore to these amino acid is dependent on the oxygen supply. In the following experiments cultivations were performed with vigorous aeration or shaking.

Changes in cellular components during growth under different culture conditions

To examine biochemically the growth responses of spores under different culture conditions, changes in amounts of cellular components were followed employing the fractionation method of Schmidt-Thannhauser. Culture media used were complete Demain's medium and the basal media supplemented with (1) L-alanine plus L-glutamate and (2) L-alanine only. In the alanine-glutamate medium, spores germinated and outgrowth ensued as normally as observed in the complete medium, and in the alanine medium only germination occurred.

Fig. 2 indicates comparative data on changes in amount of cellular fractions as influenced by those culture conditions. The acid soluble phosphorus compounds increased at a similar rate in both cases during the initial $3 \mathrm{hr}$ with about $30 \mathrm{~min}$ delay in the alanine medium, and a remarkable difference in the rate was observed after $3 \mathrm{hr}$ of cultivation;

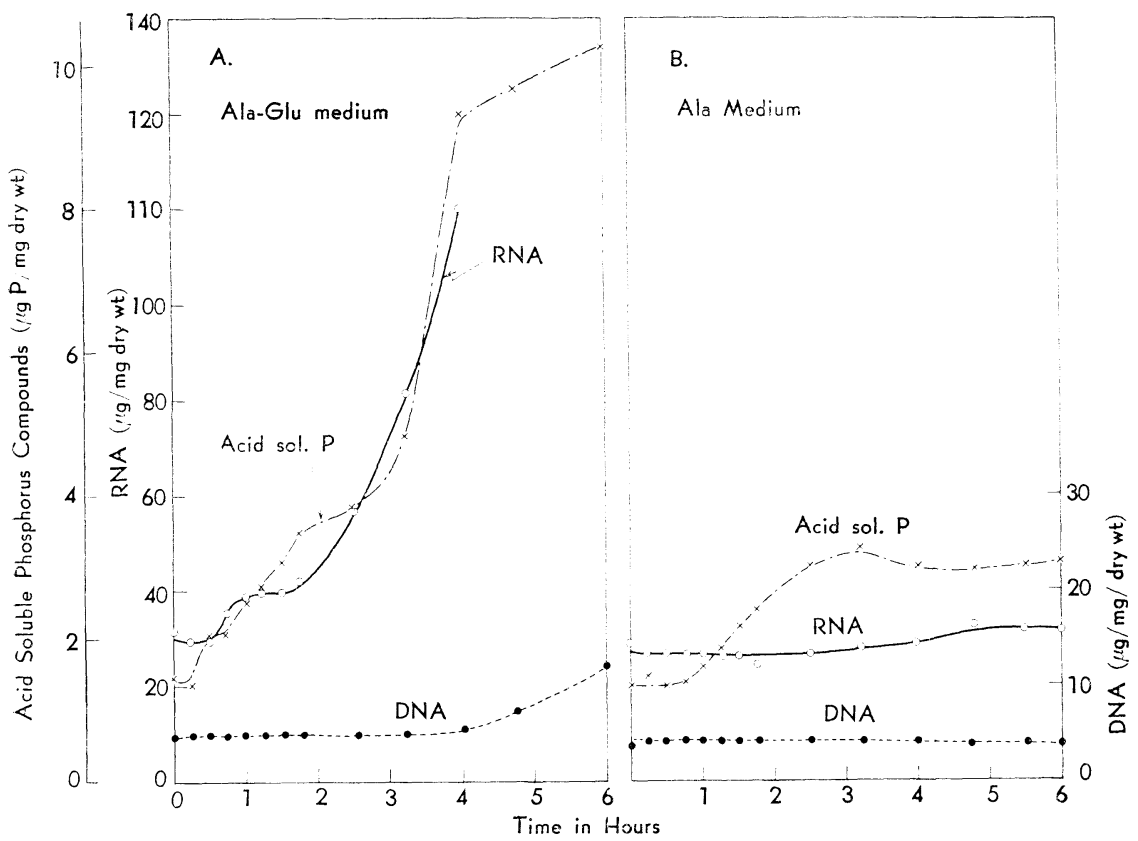

Fig. 2. Changes in amount of phosphorus fractions of $B$. subtilis spores grown in different media.

A. Shaken cultured in the alanine-glutamate medium.

B. Shaken cultured in the alanine medium. 
in the presence of outgrowth they increased abruptly and in the absence leveled off. It is noteworthy that appreciably no net increase in RNA and DNA was observed in the absence of outgrowth, while a characteristic stepwise increase of RNA and a delayed increase of DNA just prior to cell division were observed in the presence of outgrowth.

When spores were cultured in complete DemaIn's medium, courses of increases in these cellular components were quite similar to those in the alanine-glutamate medium.

Alanine ${ }^{-14} C$ uptake under different culture conditions

Since L-alanine has been found to be effective in inducing germination, the course of alanine uptake into intact spores was followed using L-alanine-U- ${ }^{14} \mathrm{C}$ as tracer. Media used were (1) complete Demain's medium containing L-alanine (1 mM) together with L-glutamate and L-asparagine, (2) basal medium supplemented with L-alanine $(1 \mathrm{~mm})$ plus L-glutamate, and (3) the latter with L-alanine ( $1 \mathrm{~mm})$ only. To each one of these media was added alanine $-{ }^{14} \mathrm{C}$ at a final concentration of $0.1 \mu \mathrm{c} / \mathrm{ml}$.

Fig. 3 illustrates the courses of uptake under these culture conditions. The most active uptake without appreciable lag was observed in the

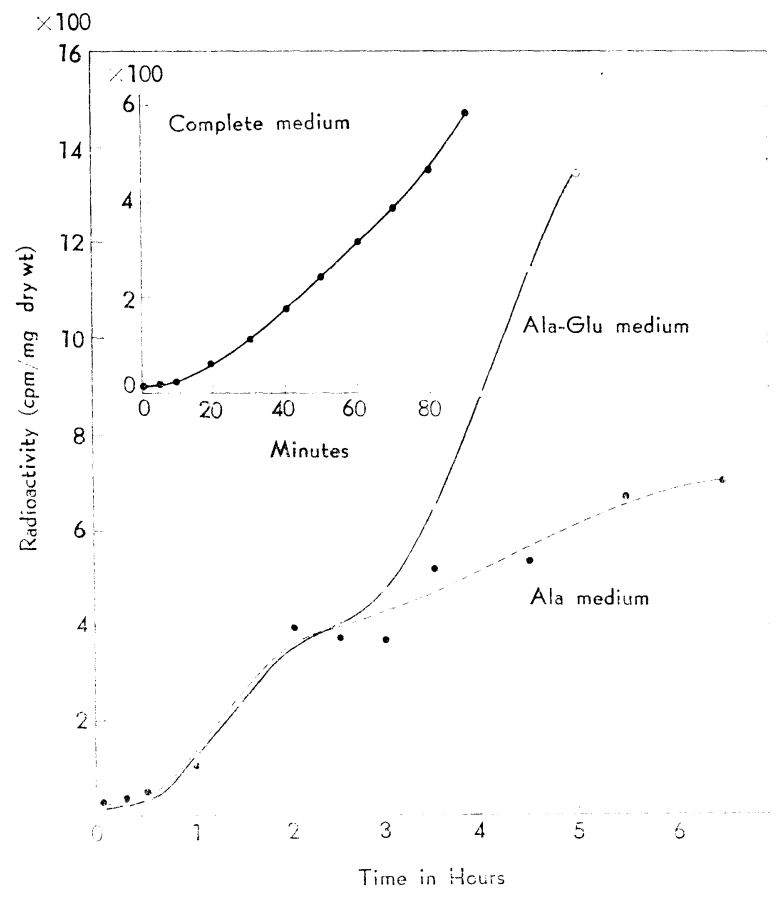

Fig. 3. Courses of L-alanine- ${ }^{-14} \mathrm{C}$ uptake into intact spores of $B$. subtilis grown in different media.

Inserted figure indicates the same course demonstrated using complete Demain's medium as control. 
alanine-glutamate-asparagine medium (DemaIn's medium). In the alanineglutamate-medium, in which germination and outgrowth occurred, a slight but definite uptake was noticed during germination and an active uptake ensued after the germination, whereas in the alanine medium, in which only germination occurred, the course of initial uptake was almost similar to that in the alanine-glutamate medium and after $3 \mathrm{hr}$ the rate of uptake decreased, showing a marked contrast to that in the alanine-glutamate medium. It should be recalled that such a divergence observed after $3 \mathrm{hr}$ between spores cultured in the two media was also demonstrated in the

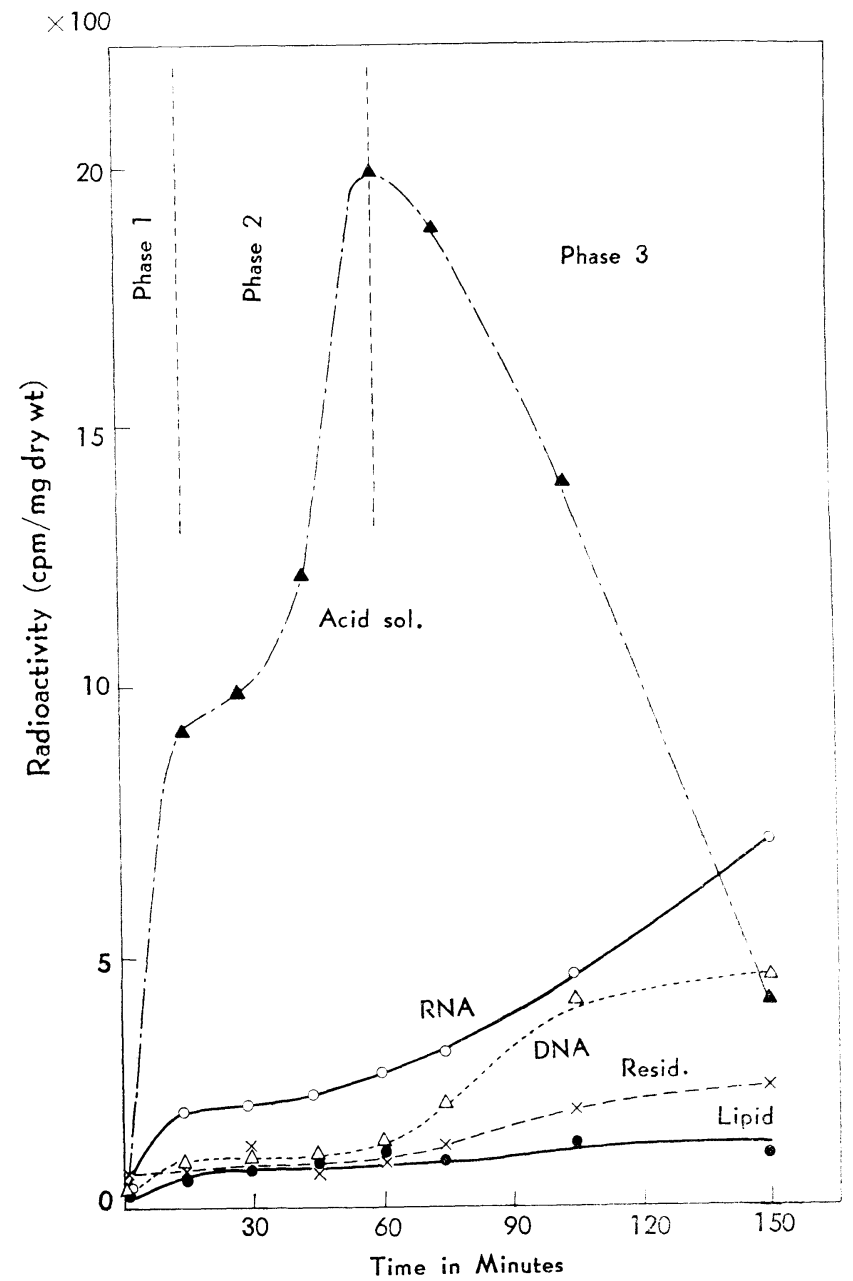

Fig. 4. Courses of $\mathrm{L}$-alanine-14 $\mathrm{C}$ incorporation into various cellular fractions of $B$. subtilis spores grown in complete DemaIN's medium.

For phases $1-3$ see text. 
course of increase in the acid soluble phosphorus compounds (Fig. 2).

Incorporation of alanine ${ }^{-14} \mathrm{C}$ into cellular fractions

To follow the fate of L-alanine taken up into spores during growth, the incorporation of alanine $-{ }^{14} \mathrm{C}$ into cellular fractions was examined. Spores were cultured in complete DemaIn's medium containing $1 \mathrm{~mm}$ L-alanine and $1 \mu \mathrm{c} / \mathrm{ml}$ L-alanine-U- ${ }^{14} \mathrm{C}$.

As seen in Fig. 4, the course of incorporation of alanine ${ }^{-14} \mathrm{C}$ into various fractions extracted by the Schmidt-Thannhauser method may be divided at least into 3 phases. The first phase $(0-15 \mathrm{~min})$ is characterized by a rapid and remarkable increase in radioactivity of the acid soluble fraction and by a definite increase in that of the RNA fraction. In the second phase $(15-60 \mathrm{~min})$ the rates of increases in the acid soluble and RNA fractions were retarded temporarily and later accelerated again. Characteristic is the third phase (after $60 \mathrm{~min}$ ) in which the radioactivity of the acid soluble fraction decreased rather abruptly, while those of the RNA, DNA and the residual fractions increased actively.

Among macromolecular constituents in spores, RNA was found to be labeled definitely during the initial $15 \mathrm{~min}$ irrespective of the absence of its net increase as already remarked in Fig. 2. To ascertain the initial labeling of RNA, the RNA fraction obtained from spores cultured for 30 min in the presence of alanine $-{ }^{14} \mathrm{C}$ was hydrolyzed with PCA, paper chromatographed and radioactivity scanned as described in Materials and Methods. The result indicated in Fig. 5 clearly shows that uracil was labeled specifically at a high rate. A peak observed at $\mathrm{Rf} 0.87$ is considered

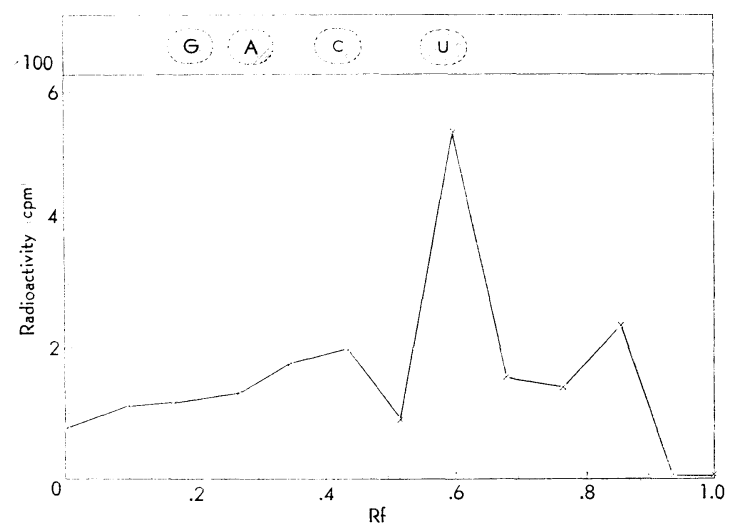

Fig. 5. Paper radiogram of hydrolysate of nucleic acids extracted from $B$. subtilis spores grown for $30 \mathrm{~min}$ in complete DeMaIN's medium in the presence of $\mathrm{L}$-alanine ${ }^{-14} \mathrm{C}$.

For experimental procedures see MATERIALS AND METHODS.

Top figure showing shaded spots indicates paper chromatogram of a base mixture developed in paralled with the radioactive test sample. Figures G, A, C and U represent guanine, adenine, cytosine and uracil. 
to be D-ribose which gives similar Rf value with the same solvent system.

\section{DISCUSSION}

Spores of B. subtilis seem to be different from conidia of Aspergillus in that the germination process is independent of the presence of $\mathrm{CO}_{2}$. On the other hand, the dependency of germination of spores on L-alanine in B. subtilis is as decisive as in Aspergillus.

YanAGita (14) describes that in $A$. niger conidia ${ }^{14} \mathrm{CO}_{2}$ is taken up immediately after the onset of germination, and $\mathrm{L}$-alanine $-{ }^{-14} \mathrm{C}$ after a short lag, and that these labeled compounds were found to be incorporated into nucleic acids and protein. Interesting findings are those of YANAGITA (7) and Hoshino et al. (6) who showed that labeling patterns of nucleic acid bases as observed by a short exposure to these tracers were almost identical with each other. These observations suggest that the metabolic activities in the early germination are directed toward biosyntheses (or modifications) of some important cellular components employing various extraand intracellular materials as building blocks. Recent investigations in this laboratory using Aspergillus oryzae conidia have shown that such important cellular substances for driving germination are related to some molecular species of RNA. It is indeed worth mentioning that the nucleic acid metabolism during the course of sporulation and germination in bacterial spores has been receiving special attention in this research field (15-18). The present work seems to correlate preceding data regarding the requirement of L-alanine with RNA synthesis in germinating spores.

In this spore, processes of germination and outgrowth can be separated by nutritional conditions. In the presence of L-alanine in a basal medium, only germination proceeds, whereas in the presence of L-alanine plus L-glutamate, germination is followed by active outgrowth. With respect to the net syntheses of nucleic acids during the germination period $(30 \mathrm{~min}$ in duration), no appreciable increase could be observed in spores grown in the L-alanine medium and in the L-alanine plus L-glutamate medium. Quite a remarkable difference in this respect was observed between these spore cultures only after the germination had been completed, as seen in Fig. 2.

Although no net increase of RNA was found during germination, it was clearly demonstrated that when fed with L-alanine $-{ }^{-14} \mathrm{C}$ spore RNA was labeled definitely during this period: a $30 \mathrm{~min}$ exposure of spores to $\mathrm{L}$-alanine $-{ }^{14} \mathrm{C}$ resulted in an uneven labeling of RNA bases, showing the strongest radioactivity in uracil. It is of interest to refer to our recent finding that in germinating conidia of $A$. oryzae ${ }^{14} \mathrm{CO}_{2}$ is actively incorporated into RNA irrespective of the absence of a net increase in RNA (19). From these observations, it may be considered that some minor portions of RNA synthesized (or modified) in the course of germination play an important role in driving the spore germination.

In an earlier paper of HARRELL and HALVORSON (20), they stated that 
there was no detectable metabolism of L-alanine during spore germination of Bacillus terminalis as examined by the consumption of L-alanine ${ }^{-14} \mathrm{C}$ and by the formation of ${ }^{14} \mathrm{CO}_{2}$. It should, however, be mentioned that in their experiment the duration of exposure to L-alanine $-{ }^{14} \mathrm{C}$ was only 45 sec. Therefore, it is highly probable that the metabolic conversion of $\mathrm{L}^{-}$ alanine into $\mathrm{CO}_{2}$ in germinating spores might not be demonstrated because of its low activity. A direct analysis of spore components after the labeling with $\mathrm{L}$-alanine ${ }^{-14} \mathrm{C}$ may afford much information on the role of $\mathrm{L}$-alanine in bacterial spore germination.

\section{SUMMARY}

Employing spores of Bacillus subtilis (Marburg strain), the role of L-alanine in the germination was examined. Spores of this organism can germinate in the presence of L-alanine or L-asparagine in a chemically defined medium but can outgrow only when L-glutamate is present in addition to either one of these amino acids.

When the spores were grown in the alanine medium, in which only germination was induced, no net increase in nucleic acids was observed, whereas in the alanine-glutamate medium, in which germination and outgrowth occurred, a stepwise increase in RNA was demonstrated showing an appreciable lag during the germination period.

When the spores were fed with L-alanine $-{ }^{-14} \mathrm{C}$, a slight but definite uptake of the tracer into spores was noticed during germination. This was confirmed by cell-fractionation experiments. A definite incorporation of L-alanine $-{ }^{14} \mathrm{C}$ into the RNA fraction during early germination was clearly demonstrated. The finding that the labeling of RNA with the tracer amino acid in the absence of net increase in RNA during germination is discussed as compared with similar observations in germinating Aspergillus conidia.

\section{REFERENCES}

(1) G. M. Hills: Biochem. J., 45, 363 (1949); J. Gen. Microbiol., 4, 38 (1950).

(2) B. T. Stewart and H. O. Halvorson: J. Bacteriol., 65, 160 (1953).

(3) M. Amaha and T. Nakahara: Nature, 184, 1255 (1959).

(4) H. O. Halvorson and B. D. Church: Bacteriol. Rev., 21, 112 (1957).

(5) R. O'Conner: Spores II, ed. by H. O. Halvorson, Burgess Pub. Co., Mineapolis (1961), p. 73.

(6) J. Hoshino, A. Nishi and T. Yanagita: J. Gen. Appl. Microbiol., 8, 233 (1962).

(7) T. Yanagita: J. Gen. Appl. Microbiol., 9, 343 (1963).

(8) R. Irie and H. Uchiyama: J. Gen. Appl. Microbiol., 10, 237 (1964).

(9) A. L. Demain: J. Bacteriol., 75, 517 (1958).

(10) E. Volkin and W. E. CoHn: Methods of Biochemical Analysis, ed. by D. Glick, Vol. 1, Interscience Pub., Inc., New York (1954), p. 287. 
(11) O. Lindberg and L. Ernster: Methods of Biochemical Analysis, ed. by D. GLick, Vol. 3, Interscience Pub., Inc., New York (1954), p. 4.

(12) K. Burton: Biochem. J., 62, 315 (1956).

(13) Y. Hachisuka, N. Asano, N. Kato, M. Okajima, M. Kitaori and T. Kuno: $J$. Bacteriol., 69, 399 (1955).

(14) T. Yanagita: Synchrony in Cell Division and Growth, ed. by E. Zeuthen, John Wiley \& Sons, Inc., New York (1964), p. 391.

(15) C. Woese and J. Forro: J. Bacteriol., 80, 811 (1960).

(16) M. R. Del Valle and A. I. Aronson: Biochem. Biophys. Res. Commun., 9, 421 (1962).

(17) G. Balassa: Biochim. Biophys. Acta, 72, 497 (1963).

(18) R. H. DoI and R. T. Igarashi: J. Bacteriol., 87, 323 (1964).

(19) K. Tanaka, F. Kogané and T. Yanagita: J. Gen. Appl. Microbiol., 11, 85 (1965).

(20) W. K. Harrell and H. Halvorson: J. Bacteriol., 69, 275 (1955). 